\title{
InSAR as a practical tool to monitor and understand large-scale mining-induced ground deformations in a caving environment
}

K Mäkitaavola Luossavaara-Kiirunavaara Aktiebolag (LKAB), Sweden

B-M Stöckel Luossavaara-Kiirunavaara Aktiebolag (LKAB), Sweden

T Savilahti Luossavaara-Kiirunavaara Aktiebolag (LKAB), Sweden

J Sjöberg Itasca Consultants $A B$, Sweden

J Dudley MDA Geospatial Services, Canada

MA McParland MDA Geospatial Services, Canada

R Morin MDA Geospatial Services, Canada

\begin{abstract}
The application of InSAR technology to monitor mining-induced deformations has been successfully applied at the Kiruna mine site for more than seven years. Ground deformations are caused by the use of large-scale sublevel cave mining to extract iron ore from the underground Kiirunavaara mine. More recently, InSAR monitoring has also been applied at the nearby LKAB Malmberget mine site, also mined using sublevel caving. In both cases, the induced ground deformations are affecting existing infrastructure, necessitating an urban transformation process to relocate surface infrastructure and/or residential areas. Control and follow-up of ground deformations has thus become vital, and InSAR monitoring has proven to play an ever-increasingly important role in this. The technique and its use at a high-latitude (snow-covered) site, and for LKAB's specific purposes, was initially investigated and verified during a five-year research project. A slightly expanded monitoring program is now in place in Kiruna, which supplements the standard GPS monitoring.
\end{abstract}

At Malmberget, InSAR monitoring has enabled verification of the overall movement trends with respect to major shear structures in the area. Additionally, increased reliability in areas with poor GPS coverage has been achieved, as well as increased data coverage in periods between GPS measurement campaigns. Combined use of InSAR and GPS data has also helped to calibrate and constrain numerical models, as exemplified in this paper. Work is now ongoing to implement the use of InSAR to monitor the criterion for allowable ground deformations at both sites, as well as in integrated interpretation of caving mechanics and deformations.

Keywords: sublevel cave mining, mining-induced ground deformations, remote sensing

\section{$1 \quad$ Background and site description}

\subsection{Problem statement}

Utilisation of large-scale sublevel cave mining (SLC) has been the backbone of the successful underground mining of iron ore at the Luossavaara-Kiirunavaara $A B$ (LKAB) mines in Kiruna and Malmberget, northern Sweden. Sublevel cave mining allows a high degree of mechanisation, and constant improvements over the years have resulted in high productivity and comparably low costs, making it possible to mine iron ore underground at large depth (currently up to $1,000 \mathrm{~m}$ ).

In addition to the challenges associated with underground cave mining, SLC mining also results in mining-induced ground deformations, caused by the required caving of the hanging wall rock mass. In the 
long-term perspective, this fact makes it impossible to have any residential buildings or infrastructure within the fracture zone and cave zone, where discontinuous deformations develop. Mining at the Kiruna and Malmberget sites has been ongoing for more than a century, and relocation of surface infrastructure and/or residential areas has been an accompanying aspect of mining at these sites during a long period of time. In recent years, this process of urban transformation has increased in scale and the requirements on control and follow-up of ground deformations have become increasingly important.

\subsection{Kiruna site description}

At the Kiruna site, iron ore is extracted from the Kiirunavaara orebody, a 4 km long, 80-160 m wide, tabular deposit, striking nearly north-south and dipping $55-60^{\circ}$ towards the east (Figure 1 ). Initially mined as an open pit, a switch to underground mining and utilisation of sublevel caving was performed in the early 1960 s. Annual production is around $28 \mathrm{Mt}$ of crude iron ore. The current deepest active production is at Level $1079 \mathrm{~m}$, which translates to around $820 \mathrm{~m}$ below the ground surface. The main haulage level is at Level $1365 \mathrm{~m}$. While current mining plans only extend to Level $1365 \mathrm{~m}$, the mineralisation is open at depth and may potentially be mined at significantly larger depths in the future. The orebody is primarily fine-grained magnetite with the footwall comprising trachyte, internally designated as syenite porphyry. The hanging wall consists of rhyolite, internally designated as quartz porphyry. All rocks are of Precambrian age. Contact zones of limited width are found on both the footwall and hanging wall side. The rock mass quality is generally good for all rock units, but locally, rock conditions vary from high-strength, brittle rock to altered, slightly weathered rock with clay- and chlorite-filled discontinuities. The dominating joint orientations are steeply dipping, striking north-south (parallel to the orebody) and east-west.

The caving and deformation process is schematically illustrated in Figure 2. The resulting mining-induced deformations may be categorised into continuous deformations, not causing fracturing and/or damage, and discontinuous deformations, for which fracturing and caving develops. With the municipality of Kiruna being located on the hanging wall side (Figure 3 ), and in close proximity to the mine, the mining-induced deformations are currently requiring a progressive relocation of the city of Kiruna to a new area, undisturbed by mining activities.

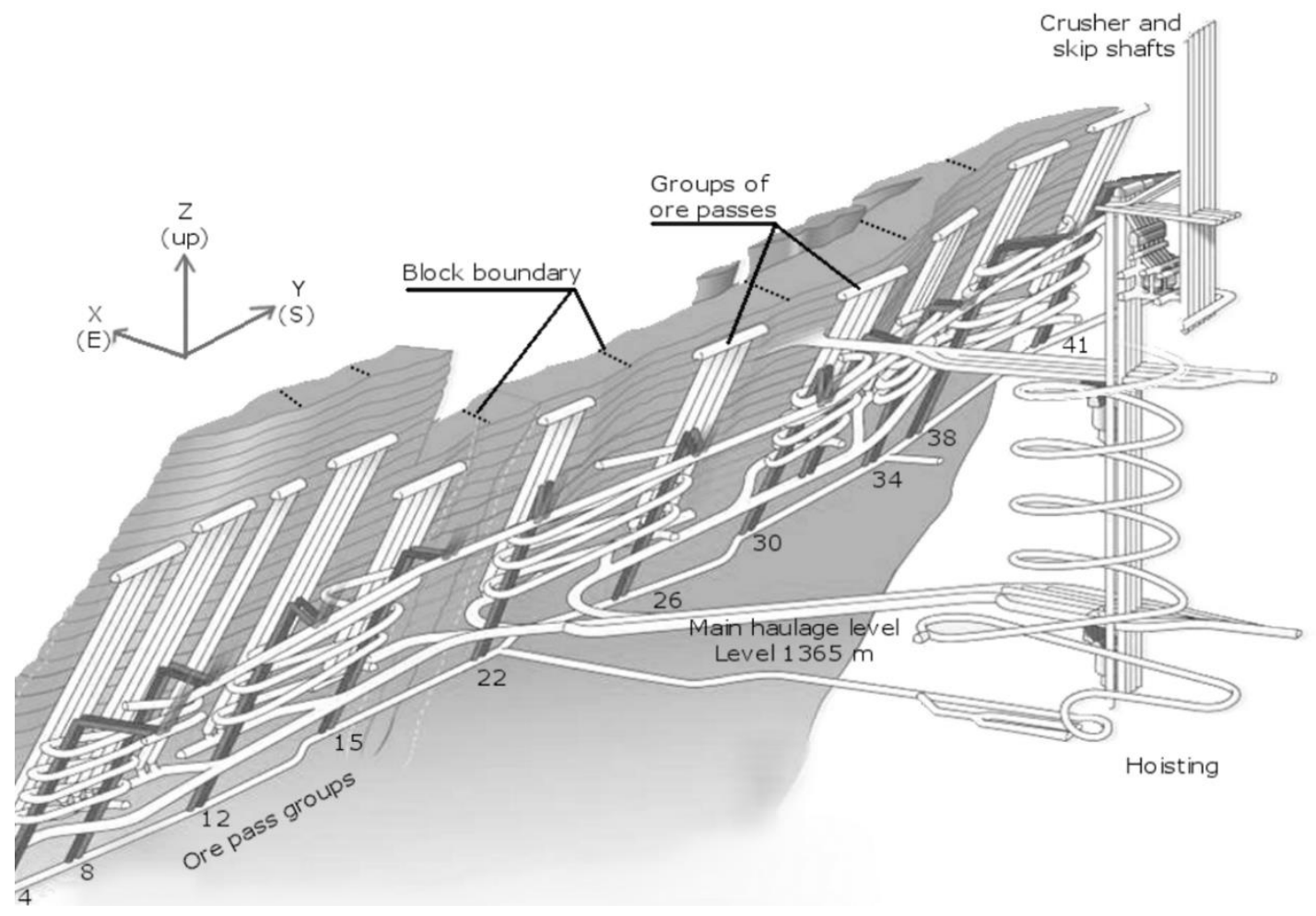

Figure 1 Sketch of the Kiirunavaara orebody and mine layout. Production blocks and associated orepass groups are numbered based on their Y coordinate (from Vatcher et al. 2016) 


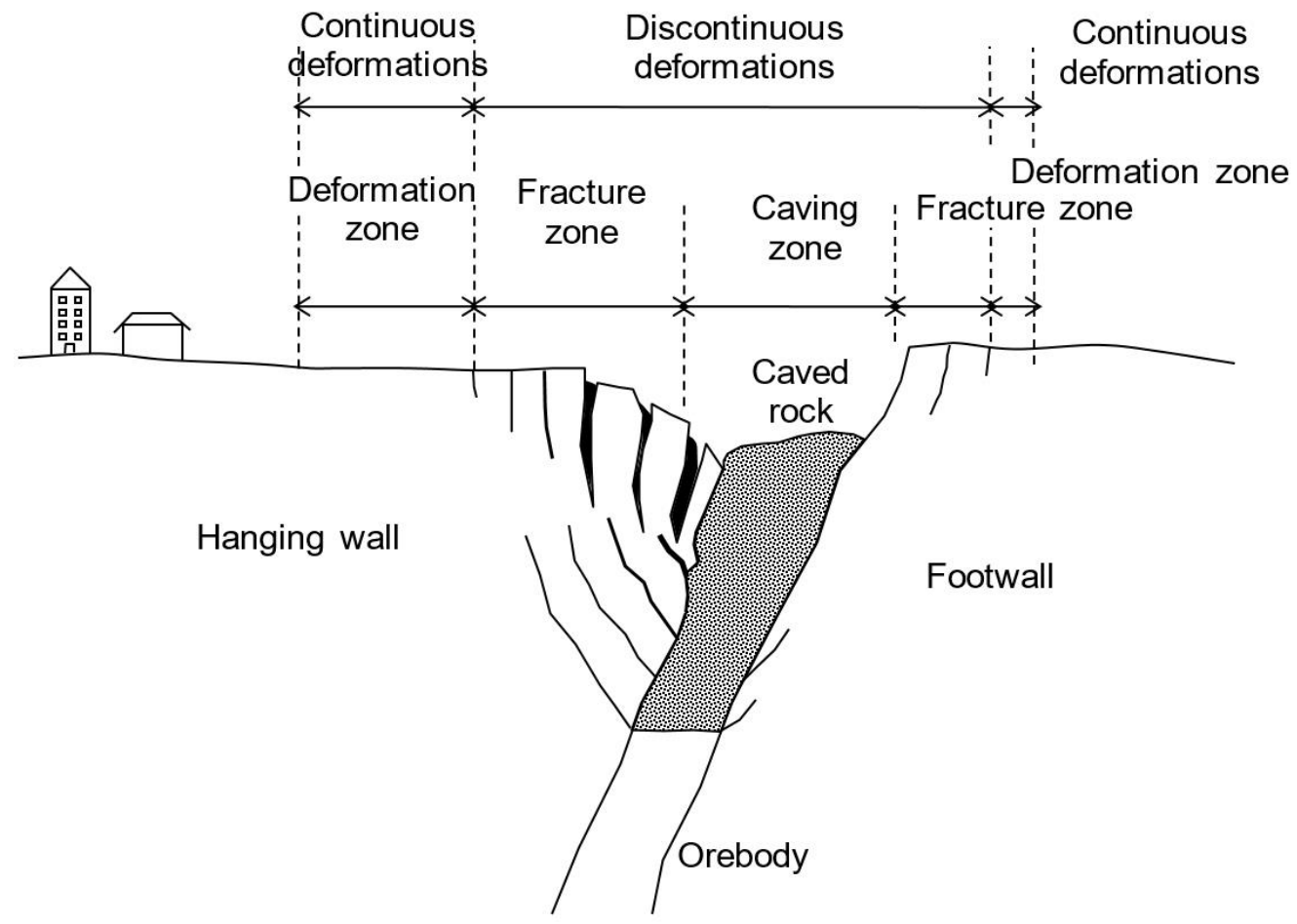

Figure 2 Mine-induced fracturing and deformations on the hanging wall and footwall in sublevel cave mining at the Kiruna site (schematic, not to scale)

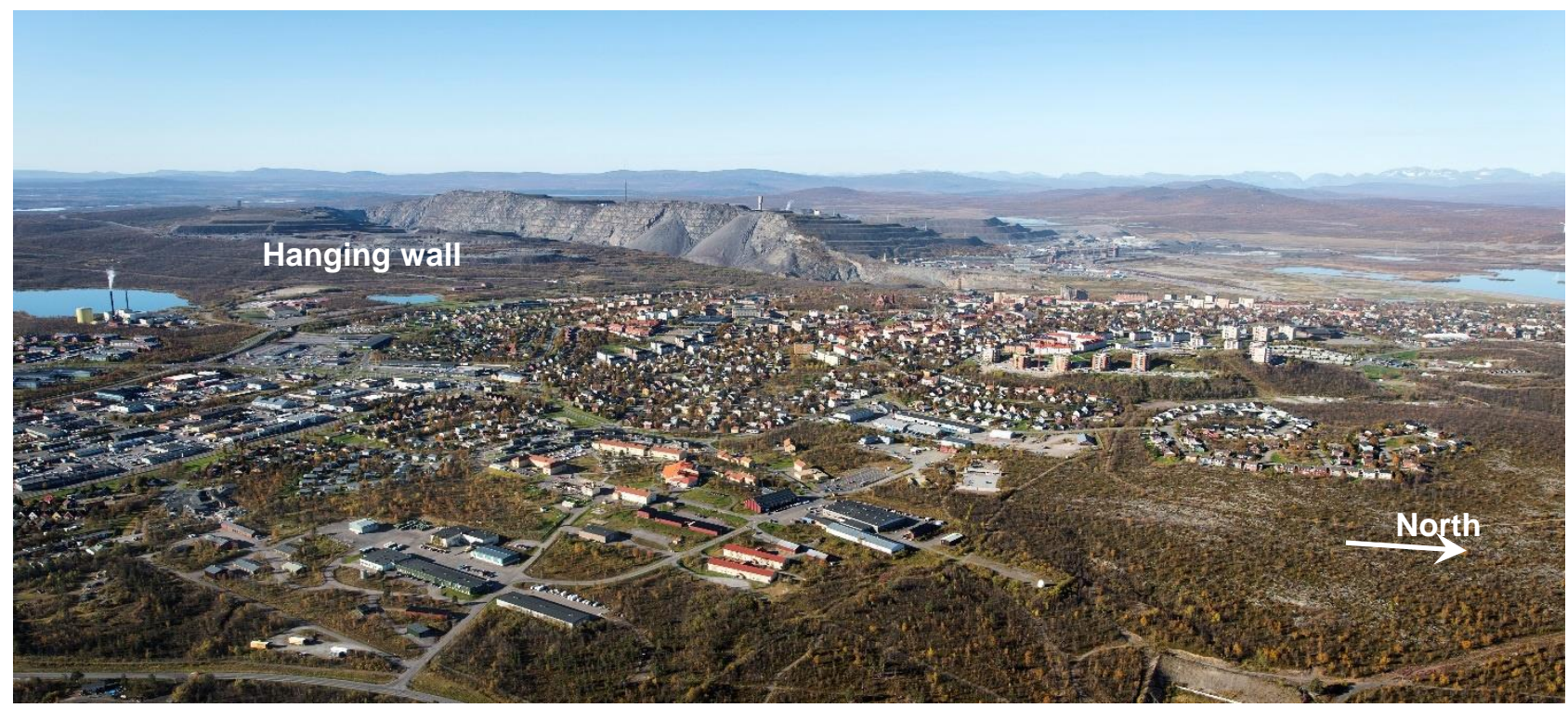

Figure 3 Aerial view of the city of Kiruna (photo courtesy of LKAB; photography by Fredric Alm of Alm \& ME)

Monitoring of ground deformations on a regular basis is necessary to be able to plan for this urban transformation accordingly. Global position system (GPS) monitoring has been the major tool for this, with a measurement network of nearly 400 hubs in place. Readings are taken up to four times a year, and the results are evaluated primarily against an environmental criterion for allowable mining-induced ground deformations in Kiruna, regulated through a ruling in the Environmental Court in Sweden. The environmental criterion states that the ground outside the mining industrial area cannot be affected by more than $0.3 \%$ strain (horizontally) and $0.2 \%$ tilt (vertically). These limits are based on investigated sensitivity of critical infrastructure. The strain values are the total strains since the start of measurement (at each hub). It is thus crucial that ground deformation measurements are commenced early (before mining-induced effects develop), to establish baseline values. 


\subsection{Malmberget site description}

The Malmberget ore field comprises some 20 orebodies, of which about 10 are actively mined today, all using sublevel caving as the mining method. The ore reserves were first discovered in the middle of the 17th century, but mining in the area did not start until the 18th century. Industrial-scale mining commenced in the late 19th century. Initially, all ore was mined in open pits but a gradual switch to underground mining took place during the early 20th century. At first, mining with waste rock backfilling was used, but this was later replaced with shrinkage stoping. In the mid-1960s, sublevel caving was decided upon as the standard mining method, which has been used ever since. The total annual production amounts to $15 \mathrm{Mt}$ of iron ore. The current main haulage level is denoted M1250 and located at Level $1250 \mathrm{~m}$. The ground surface is between Levels 50 and $250 \mathrm{~m}$ in the mine coordinate system, with the zero-level at the top of the Välkomma Mountain in northwestern Malmberget (at 616.4 mamsl). Currently, the deepest active production area is Level $1074 \mathrm{~m}$ (Figure 4).

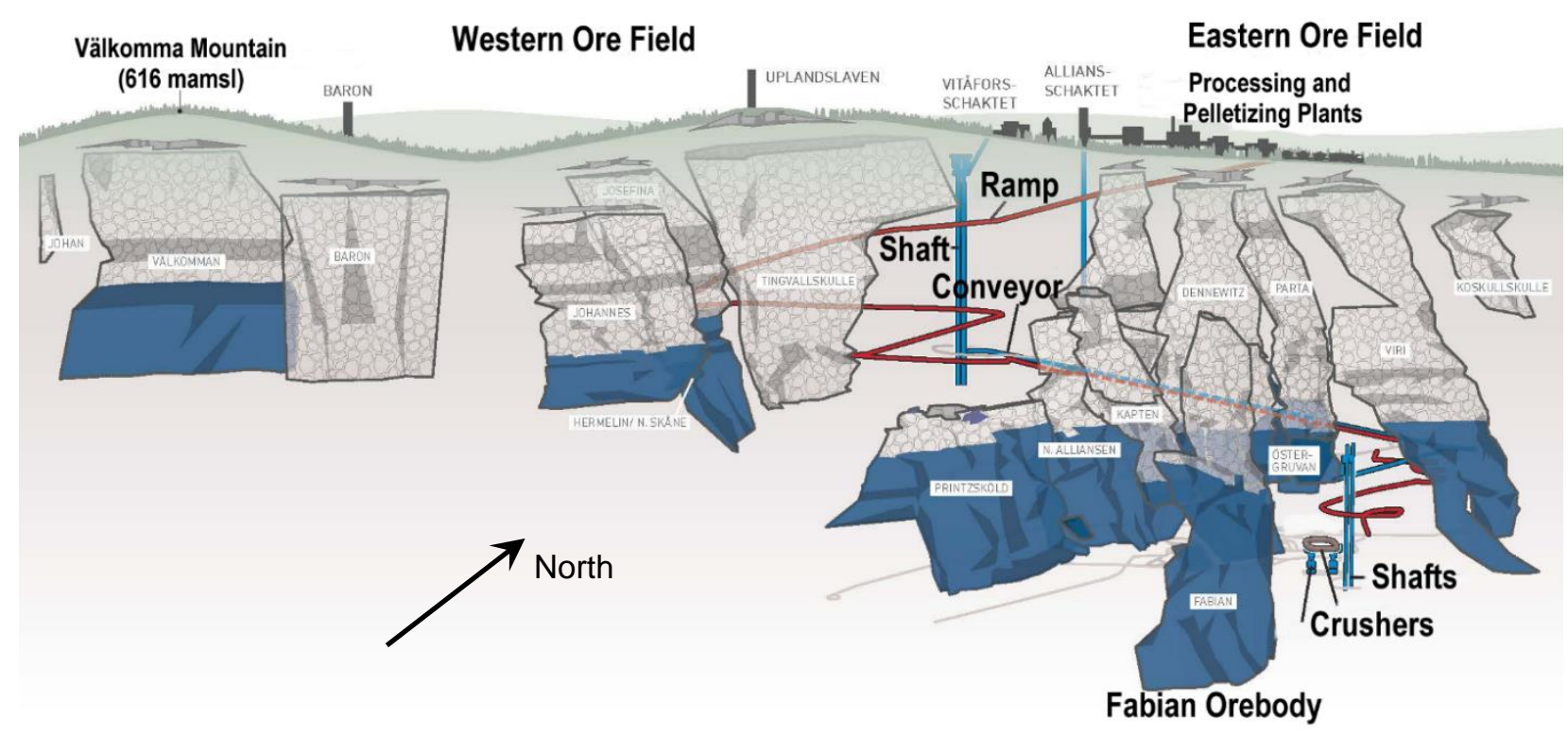

Figure 4 Orebodies and transport and haulage system in the LKAB Malmberget mine (blue colour shows unmined portions)

The ore in the Malmberget ore field is primarily magnetite of fairly high strength and stiffness, with hematite occurring in some orebodies, most notably in the western portion of the ore field. The host rock comprises igneous felsic-intermediate fine-grained rock types, with a varying degree of mica (mostly biotite) content. Generally, the rock is of good quality and competence, but a weak biotite schist also exists, primarily near the orebody contacts in some of the production areas. The rock mass is jointed with two to three dominating joint sets oriented subparallel to the orebodies and vertically. A structural-geological model of the area has revealed several potential large-scale deformation zones, as interpreted from topography and geophysical data. Some, but not all, of these have been verified through field observations and core drilling.

The caving process and the associated ground deformations are, partly, of different nature at the Malmberget site, compared to the Kiruna site. Many of the orebodies have a strong plunging component, resulting in mining under a progressively thicker cap rock (Figure 5). Moreover, some of the orebodies, in particular the Printzsköld orebody, are non-daylighting, meaning that there is no initial cave crater on the ground surface. The most likely effect of this is a distinct time delay in the development of caving and ground deformations relative to the active mining levels.

With the municipality of Malmberget being close to the active mining areas and existing cave craters (Figure 6), a more-or-less continuous urban transformation has been ongoing in the town of Malmberget during the last 100 years, in which residential buildings have been torn down and/or moved as mining has affected areas on the ground surface. This process is now in a more intense phase, as mining progresses 
deeper and closer to the central portions of the town. Similar to the Kiruna site, monitoring of ground deformations is conducted using the GPS technique. However, extensive and systematic GPS monitoring only commenced in 2009 at Malmberget. Currently, some 230 measurement hubs are being monitored, with measurements taken every quarter. An environmental criterion, similar to the one for the Kiruna site, is now also in effect at Malmberget to govern the urban transformation process.

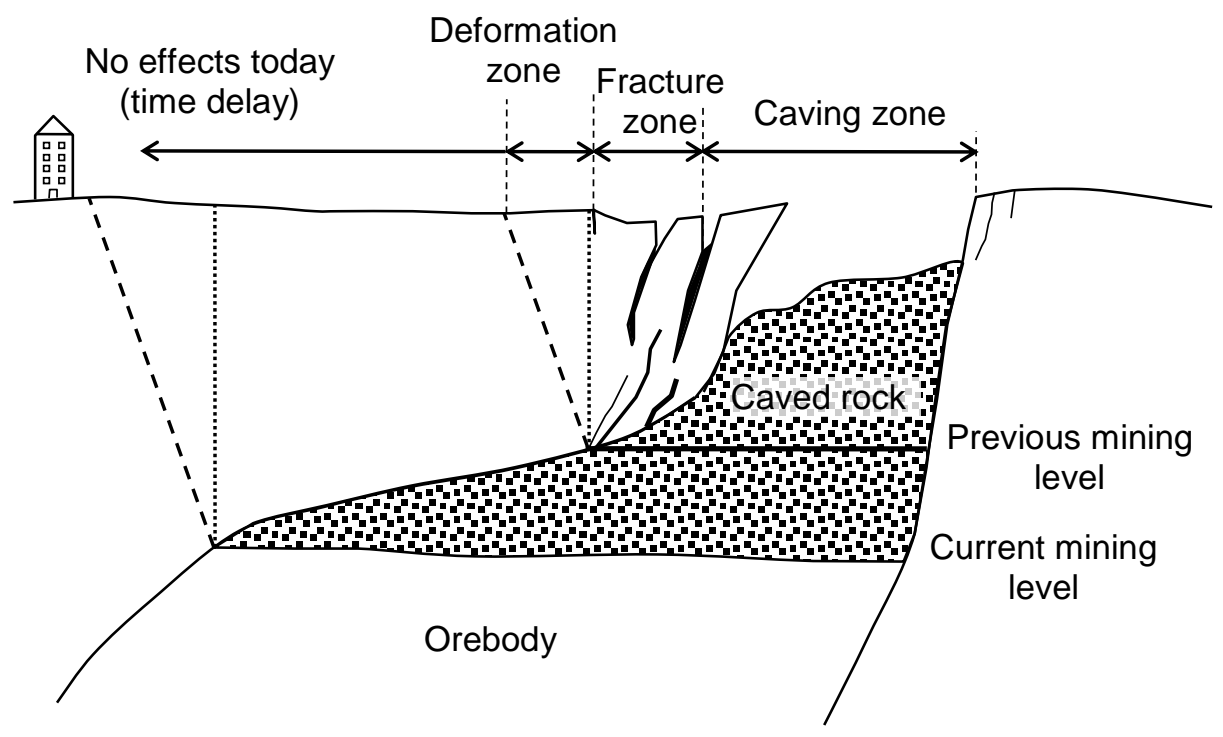

Figure 5 Mine-induced fracturing and deformations for a plunging hanging wall, typical of the Malmberget site (schematic, not to scale)

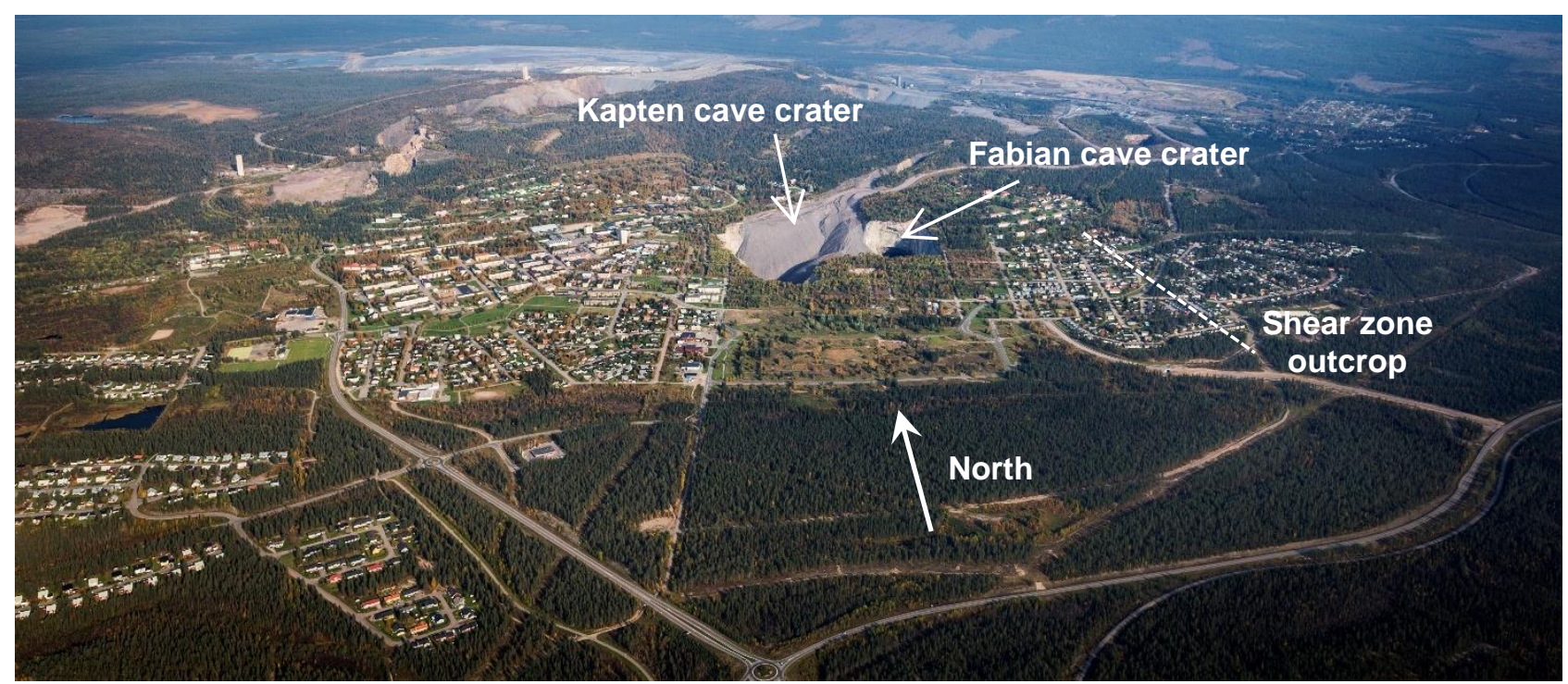

Figure 6 Aerial view of the municipality of Malmberget (photo courtesy of LKAB; photography by Fredric Alm of Alm \& ME) 


\section{$2 \quad$ InSAR application at Kiruna - from research to monitoring tool}

\subsection{Research and development work}

Global positioning system monitoring has generally worked well, with high reliability and precision (in the order of 5-10 mm). However, these measurements are time-consuming and require significant manpower. Moreover, they provide discrete measurement data (at the measurement point) but not a wide area coverage. To investigate possible supplementary monitoring techniques, LKAB started a research and development project, aiming at studying the application of the InSAR technique for monitoring ground deformations. The objective was to try to reach the same, or better, measurement precision as in GPS measurements, as well as to further develop the InSAR technology for use in winter conditions at high latitudes.

The project comprised two major components: (i) monitoring, and (ii) research and technology transfer. The monitoring work was carried out by MDA Geospatial Services (MDA) using data from the RADARSAT-2 satellite. MDA also provided technology transfer from MDA to LKAB. The supplementary research work was conducted by Cranfield University, UK and Luleå University of Technology, Sweden in the form of doctoral thesis work and graduate student projects at both universities.

Monitoring was conducted during the period of 2009 to 2014 with data obtained from the RADARSAT-2 satellite, with a return period of 24 days. The monitoring program involved using differential InSAR (DInSAR), coherent target monitoring (CTM), persistent InSAR technique (PSInSAR), and supplementary corner reflectors (CRs) in areas where there were little or no natural or artificial backscatters. A total of 60 CRs (two at each installation point) were initially installed in the Kiruna area, with 12 more reflectors (at six locations; two CRs at each point) added later (Figure 7).

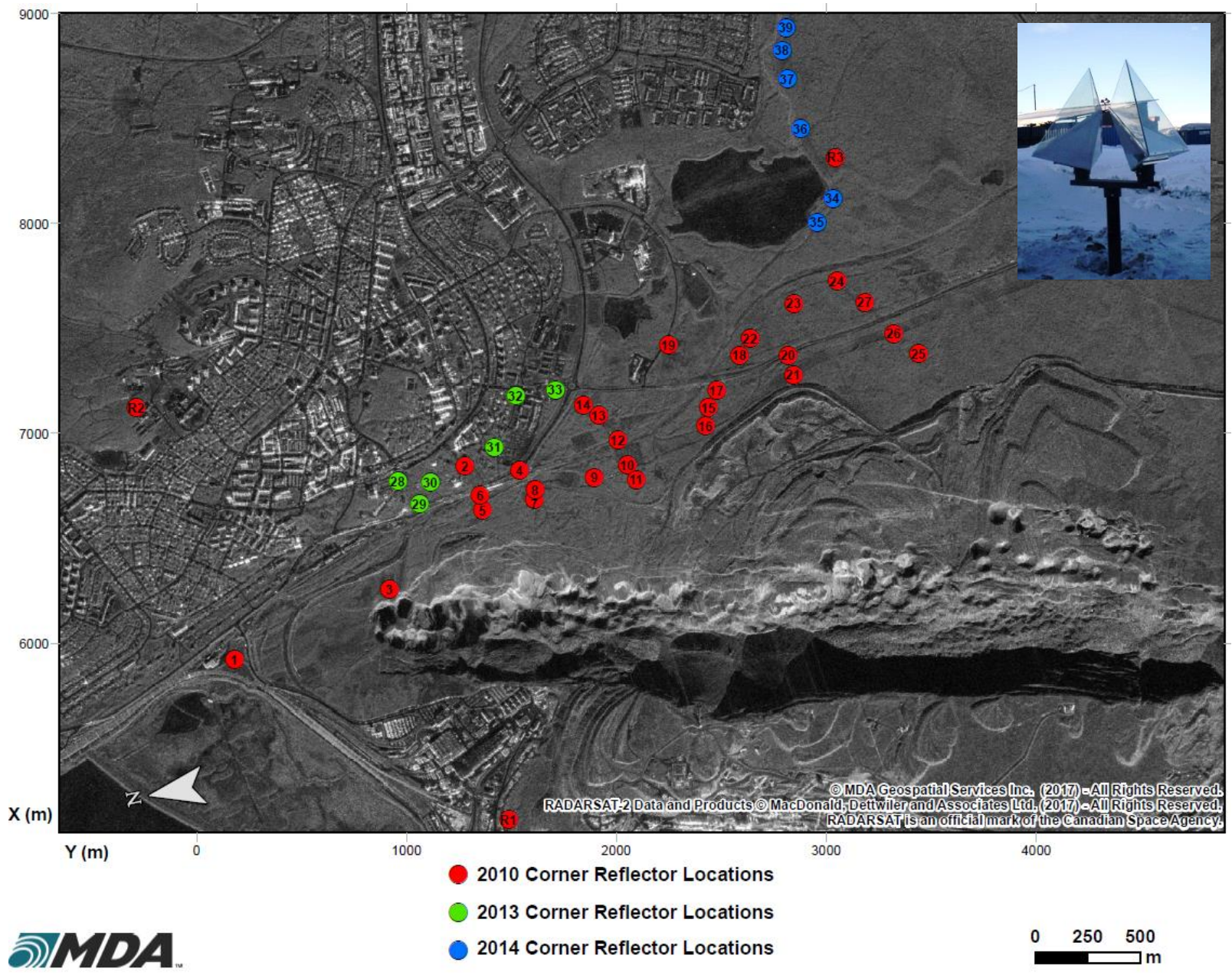

Figure 7 Corner reflectors (see inset) installed in the Kiruna area 


\subsection{Monitoring results}

Data were compiled, analysed and interpreted, and results delivered by MDA to LKAB every six months. The deliverables included: (i) RADARSAT-2 imagery for each beam mode used, (ii) conventional deformation maps, and (iii) time series profiles of individual point targets (including both CR and CTM). Through interactions with MDA, continuous improvements were achieved during this project.

Satellite data is collected for different beam modes, with different incident and aspect angles. It was discovered early that the precision in the north-south direction was not satisfactory, primarily due to the insensitivity of the sensor to along-track movement in the near-polar orbit of the satellite. Line-of-sight measurements and decompositions into east-west and vertical deformations were more reliable. Furthermore, by comparing two independent 3D decompositions, uncertainties in the east-west, vertical, and north-south deformation motion of CRs were found to be 2, 14, and $91 \mathrm{~mm}$ respectively. For the CTM targets, these uncertainties were found to increase slightly to 4,17, and $113 \mathrm{~mm}$. Uncertainties are minimised for directions with a close to orthogonal basis, but the north-south deformation measurements remain poorly constrained.

However, by using a 2D decomposition for motion in the east-west (horizontal) and vertical directions, the precision could be further improved (see also Henschel et al. 2015). For a preferred set of 2D decompositions (among a large number tested), the uncertainty in the CR measurements was found to be approximately $2 \mathrm{~mm}$ in both the east-west and vertical directions. For the CTM, these uncertainties increase slightly to 4 and $3 \mathrm{~mm}$ in the east-west and vertical directions respectively. Consequently, using a dual-beam coverage, the horizontal east-west and vertical deformation is captured with good precision - comparable to the precision of GPS measurements. This method was then applied to all data for the Kiruna site, with previously collected data re-analysed in the final deliverable. Additional research and development work is reported in Wickramanayake et al. (2016) and Mäkitaavola et al. (2016).

Following the successful outcome of the above described research project, continued InSAR monitoring has been carried out during 2015-2017, thus effectively extending the total monitoring period to nearly eight years. Since March 2010, 107 east-looking (beam mode U25A) images and 107 west-looking (beam mode U6D) images have been acquired. In this monitoring campaign, the analysis focused on point target analysis, i.e. CTM and CR.

The CRs were located in areas where sufficient natural targets were sparse (cf. Figure 7), and in lines parallel to the expected deformation from near the fracture zone (cf. Figure 1). They were initially spaced at distances where the deformation between two imaging dates would not exceed the phase ambiguity and would be similar to that employed with the GPS measurement hubs. Some were co-located with the GPS hubs to provide a means of comparison. Corner reflector monitoring data was available year-round with the same precision.

The CTM analysis and target selection is performed independently for each beam mode and designed to select high-quality point targets whose returned phase to the radar is stable in time (e.g. urban infrastructure). The CTM analysis also utilises the installed CR reference phase targets (R1, R2 and R3). These targets provide stable returns which act as phase references and are located exterior to the deformation zone. Accuracy is lower in the winter, with higher chances of unwrapping errors. Hence, the CTM measurements were restricted to snow-free periods to ensure similar accuracy to the CR measurements. An example of the recorded movements is shown in Figure 8, combining both CR and CTM data.

An important potential application of the InSAR measurements is the ability to assess the location of where the environmental criterion (cf. Section 1.1) is satisfied. The same methodology used for GPS measurements has been tested using CR measurement data. The agreement between InSAR-derived strains and GPS-derived strains is reasonably good, with the InSAR data generally giving slightly larger strains (Mäkitaavola et al. 2016). This may be due to different distances between calculation points, different monitoring periods, and/or local variations in ground conditions. Nevertheless, the results indicate that InSAR data can be used to help assess the environmental criterion limits, but more work is required to develop a robust method for strain calculation, possibly also requiring additional CRs and/or including CTM targets to increase coverage. 


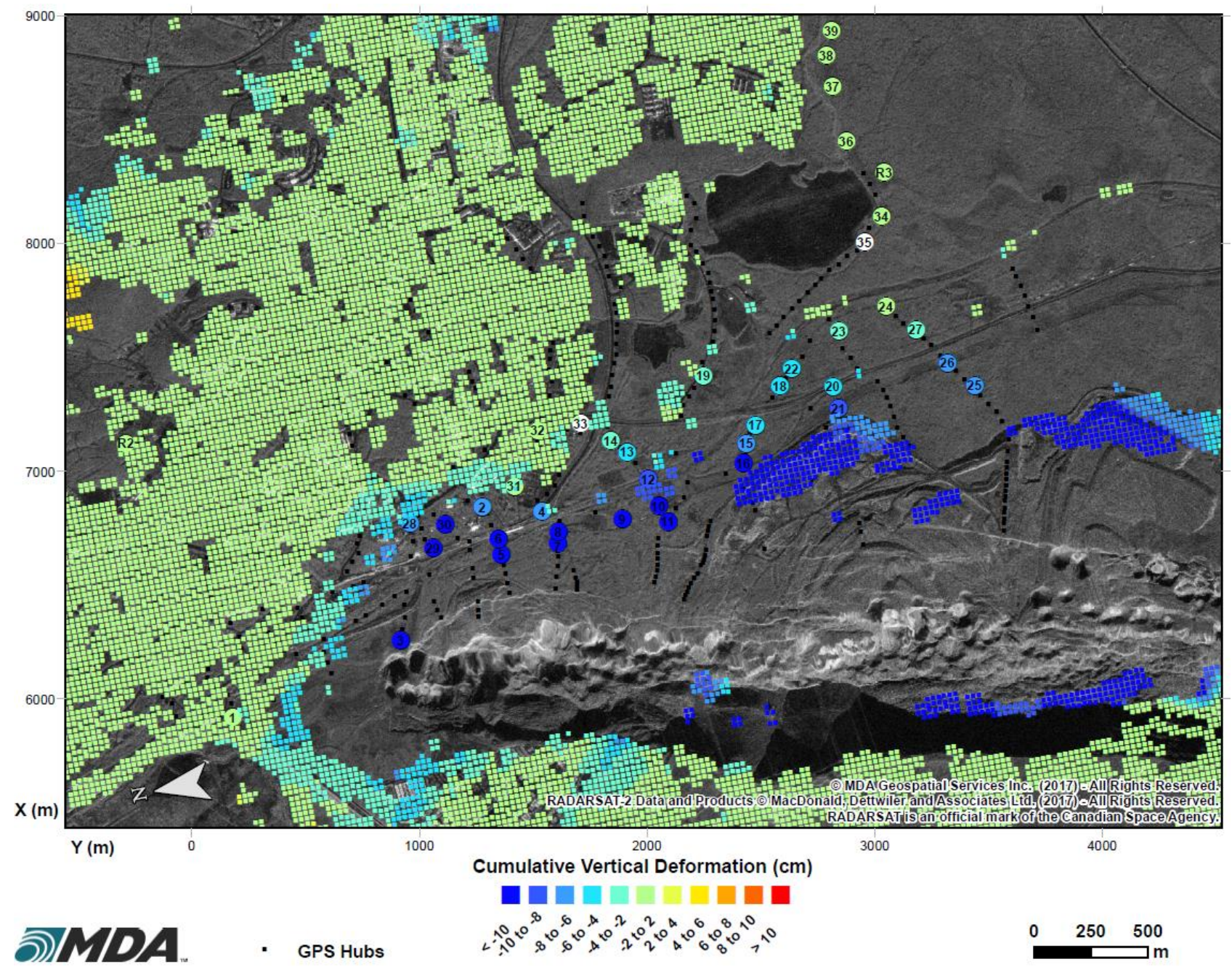

Figure 8 Example of vertical cumulative deformation from InSAR measurements for the Kiruna site

\section{Ground truthing the results}

InSAR essentially records a phase change, which in turn can be associated to a deformation relative to a starting monitoring date. To ground truth the results, a comparison of InSAR monitoring data with GPS monitoring data was conducted. Wickramanayake et al. (2015) showed that the difference between GPS and InSAR CR data was large for two of the applied analysis techniques, whereas a relatively good agreement was found when the InSAR data was extracted using only high average coherence interferograms (using a technique labelled CR-InSAR-SBAS-COR). The large difference for the other techniques may be because the InSAR winter measurements (due to snow) appear to have larger phase errors than the summer measurements. This additional phase can be reduced by using only those interferograms with higher average spatial coherence values and the satellite-based augmentation system (SBAS) techniques.

A simpler comparison of GPS and InSAR data was conducted by plotting monitoring results from CR and GPS points that are as close together as possible. This comparison assumes that each deformation record is equally accurate. Two examples with time series plots for both CR and GPS data are shown in Figure 9. The GPS data are accumulated deformations from a starting date as close as possible to the start data of the InSAR measurements. The precision in the GPS measurements has been estimated to be $7 \mathrm{~mm}$ in the horizontal direction, through a repeatability test. These examples indicate that both the trends and magnitudes of ground deformation are similar for the InSAR and GPS measurements, which lend some reliability to the InSAR data. A discrepancy is found for the vertical deformations in Figure 10, bottom figure. This may be due to lower precision in GPS measurements in vertical directions. However, this needs to be investigated further. 

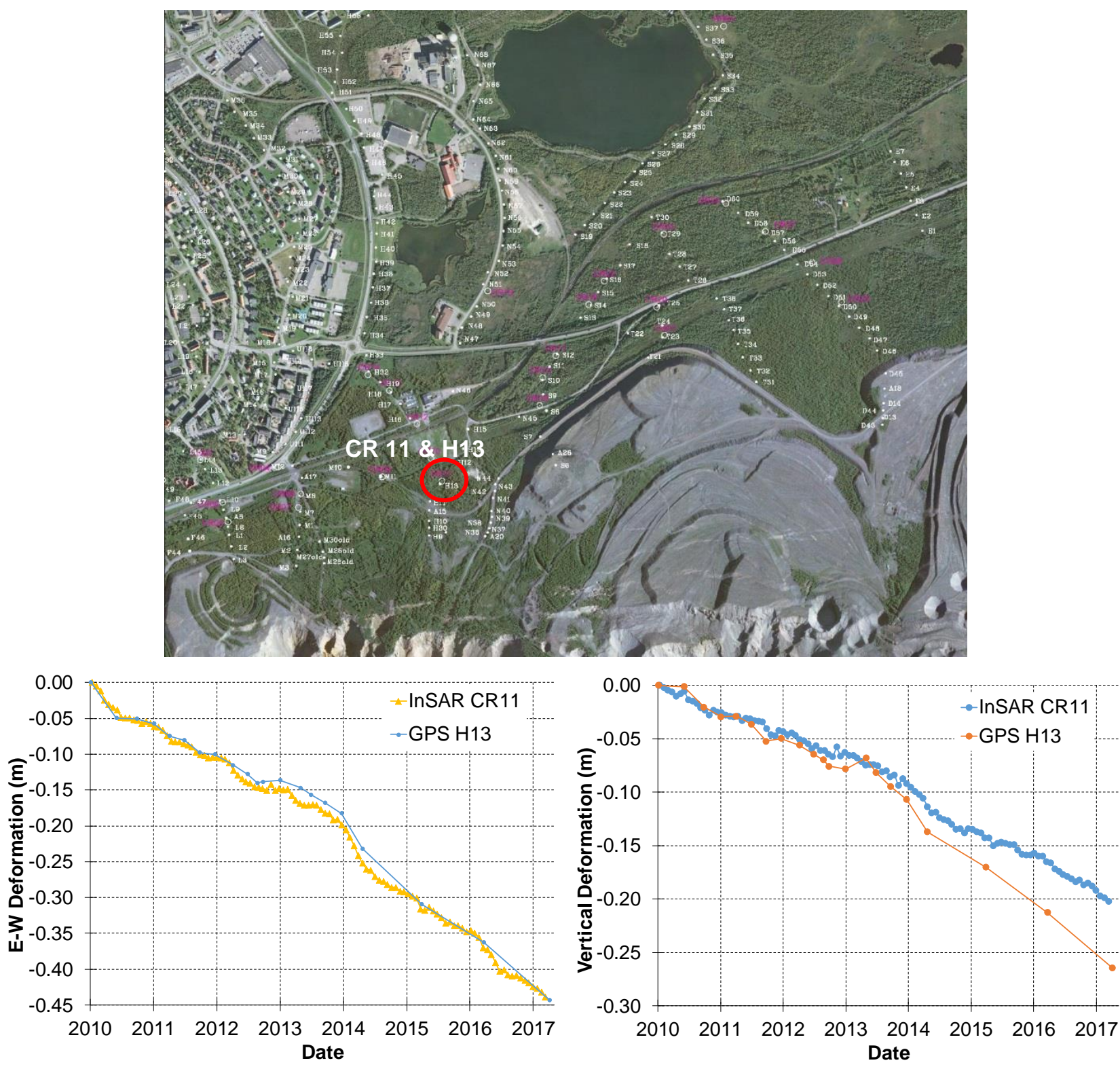

Figure 9 Cumulative deformation measurement for CR11 and GPS hub H13 (top figure) in the east-west direction (left bottom figure) and vertical direction (right bottom figure)

Coherent target monitoring results were also used as a means of ground truthing the results, through comparison with GPS data. A few selected CTM targets were chosen for this initial comparison. An example is shown in Figure 10. The GPS and InSAR results compare quite well, in particular for the east-west decomposition. For the vertical decomposition, larger variation is noted for the GPS data, likely as a result of the lower vertical precision associated with GPS. Additional work is required to compare more CTM targets with GPS measurement hubs, but these initial results are promising and lend credibility to both measurement methods. 

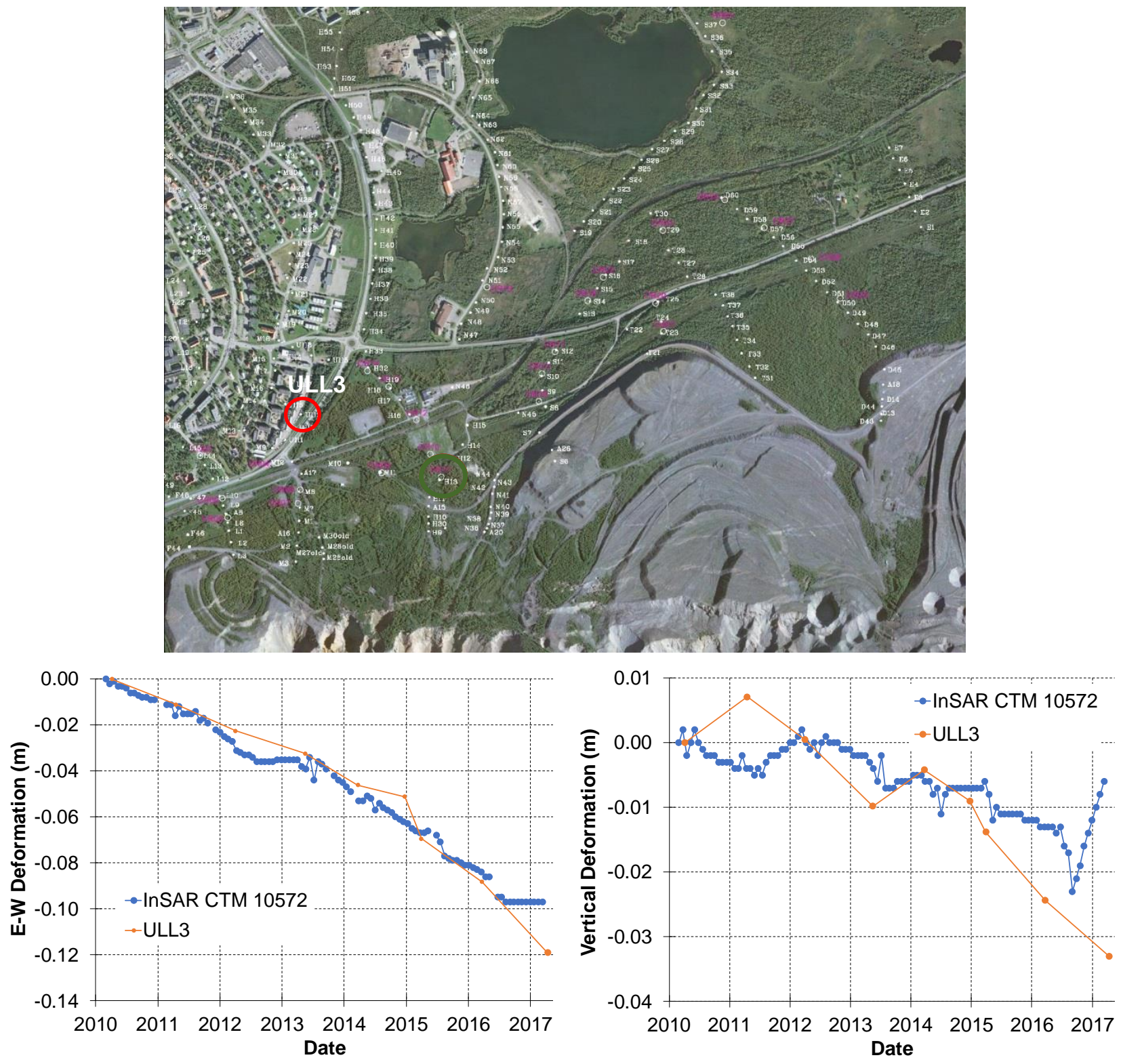

Figure 10 Cumulative deformation measurement for CTM 10572 and GPS hub ULL13 (top figure) in the east-west direction (left figure) and vertical direction (right figure)

\section{$4 \quad$ InSAR monitoring at the Malmberget site}

Following the successful implementation of InSAR at the Kiruna site, it was only natural to also consider similar monitoring at the Malmberget site. The need for this was further augmented when the GPS data indicated partly unexpected larger movements in a particular area on the ground surface. With the caving of the Fabian orebody in 2012, a new cave crater formed close to the already existing Kapten cave crater (Figure 6). The cratering was expected and caused in itself very little disturbance with no significant increase in ground deformations at distance from the cave crater (Sjöberg \& Savilahti 2014). The cave crater expanded slightly in the next two years, but with no significant ground deformations, or any signs of cracking, noted outside the fenced-in area. However, towards the end of 2014, GPS measurement data indicated a clear discontinuity in the deformation pattern, coinciding with the believed location of a large-scale shear zone (cf. Figure 6).

Initially, historic data from the ERS-2 and ENVISAT satellites for the period 1995-2010 was used together with RADARSAT-2 data for the period 2011-2013. The data from the ERS-2 and ENVISAT satellites proved to be incomplete, with large gaps in the dataset and poor coherence between images. The measurement noise is likely higher than any real ground deformations. However, the data from RADARSAT-2 proved to be of 
better quality and the results strongly indicated ground deformations along the believed location of the shear zone. Vertical deformation magnitudes from these InSAR analyses were in the order of $85 \mathrm{~mm}$ (Figure 11), comparable to what had been recorded through GPS monitoring.

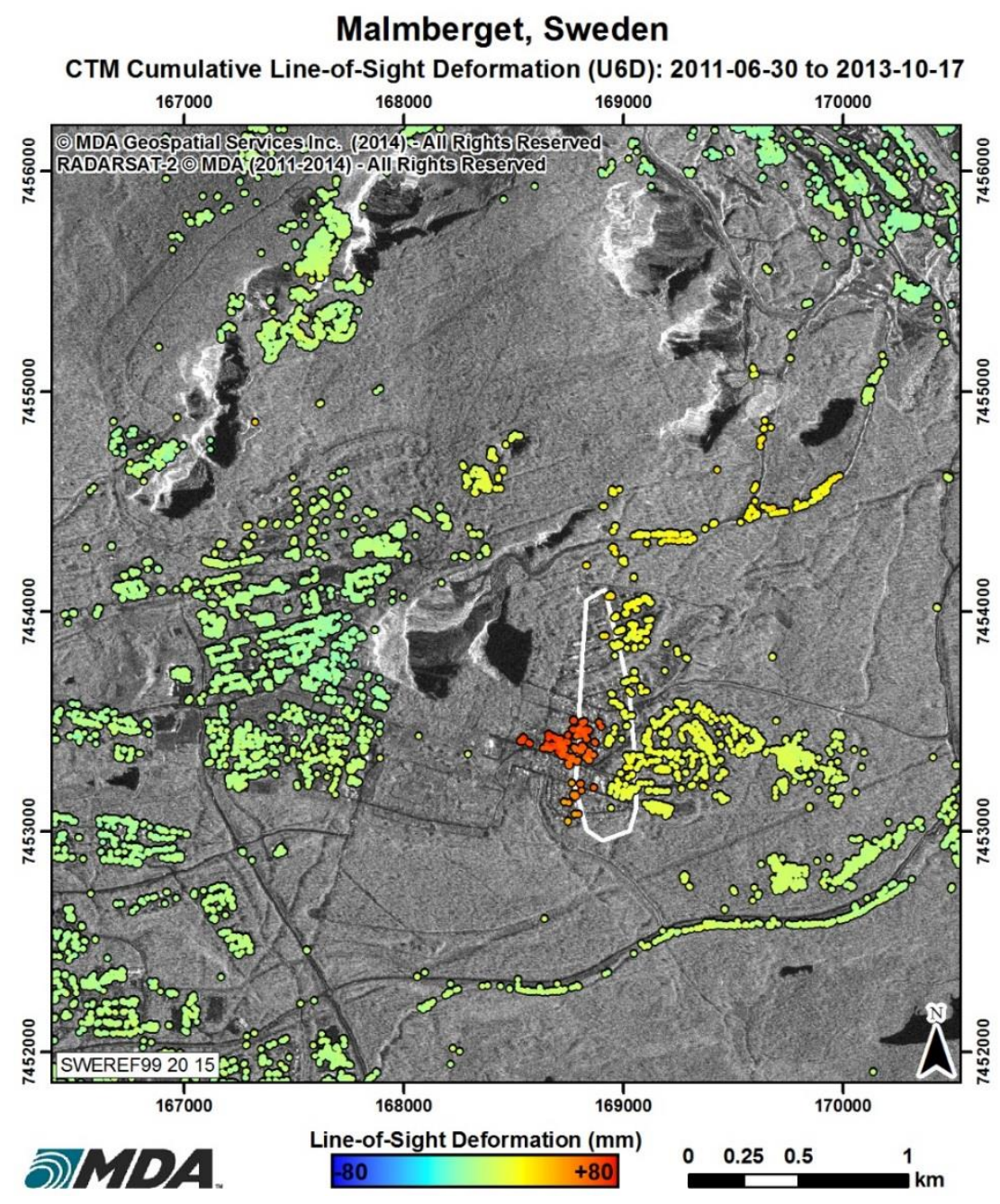

Figure 11 Cumulative line-of-sight deformation inferred from RADARSAT-2 images for the period of 2011-2013 in Malmberget, with the approximate location of shear zone in the white-marked area

Following this initial trial, InSAR monitoring was conducted on a more regular basis, using RADARSAT-2 data and two beam modes (U6A and U6D). Only CTM monitoring was used; no CRs were installed in Malmberget at this time. DInSAR (wide area) monitoring was used as a supplement to CTM monitoring. The CTM analysis and target selection is performed independently for each beam mode. Targets were selected to achieve a returned phase to the radar that is stable in time. The CTM analysis also requires the identification of reference phase targets. These targets provide stable returns which act as phase references and are located exterior to the deformation zone (in lieu of reference CRs).

For the U6A beam mode, 86,041 CTM locations were identified, of which 548 were identified as reference CTMs. For the U6D beam mode, 56,699 CTM locations were identified, with 703 of these serving as reference CTMs. By combining line-of-sight observations from both east-looking and west-looking beam models, ground movements could be decomposed into east-west and vertical components. For this, targets in both beam models were assigned to a common spatial grid $(25 \times 25 \mathrm{~m})$ and temporally interpolated to matching observation dates, resulting in 14,644 matched CTM targets. In addition, time series profiles of the east-west and vertical deformation for selected CTM point locations were provided (not shown here). 
An example of cumulative deformation for the monitoring period is shown in Figure 12 . The results clearly show increasing deformations in the eastern portion, with a clear differential movement across the suspected shear zone (dark blue areas in Figure 12). Moreover, increased deformations are also found on the western side of the cave craters (red areas in Figure 12). A study of annual deformation plots shows the development of deformation in these two areas, commencing after the Fabian cave breakthrough in 2012.

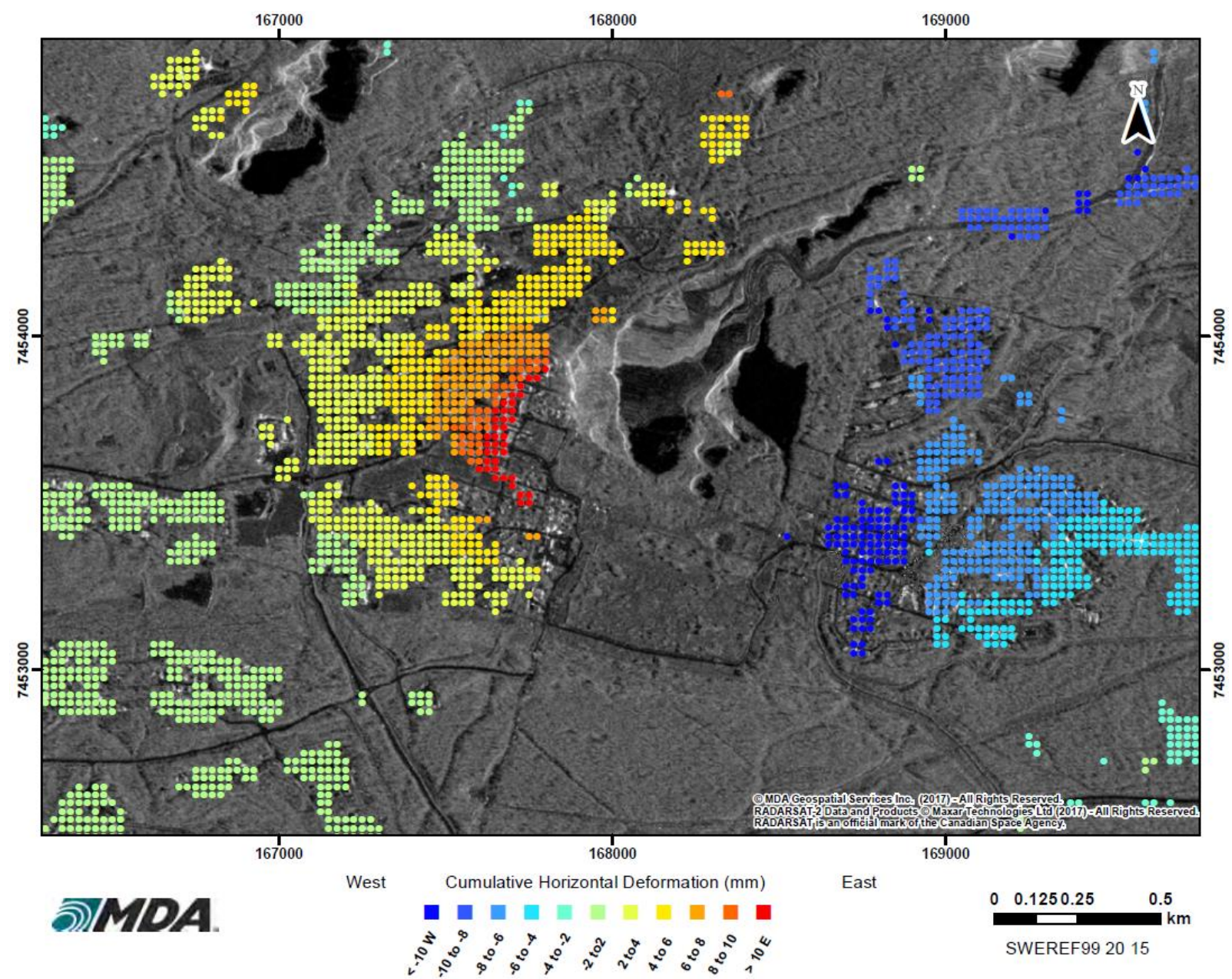

Figure 12 Example of east-west cumulative deformation from InSAR measurements for Malmberget. Blue indicates deformation in the western direction, while red indicates deformation toward the east

\section{$5 \quad$ Constraining numerical models - a case example}

To further understand deformation patterns in Malmberget, three-dimensional numerical modelling has been used. In particular, the effect of shear zones on the mining-induced deformations was studied. The model was set up using the three-dimensional distinct element code 3DEC (Itasca Consulting Group, Inc. 2016) with shear zones simulated explicitly in the model as large-scale joint planes. The numerical model included the regional topography and the Kapten and Fabian orebodies together with known shear zones in the area of interest. Caving above the Fabian orebody was also simulated by successively removing caved areas in the model.

In addition to the above-mentioned shear zone (cf. Figure 6), Magnor and Mattson (2010) identified several large-scale structures in the area. The major shear zone is denoted DZ026. This feature and three more, located close to the studied area, were included in the model since these were the ones believed to potentially influence deformations (Figure 13). A preliminary identified joint set oriented $120^{\circ} / 70^{\circ}$ (strike/dip) was also included. Different scenarios were run with one, two, three or four structures included, as well as a case with all four structures and the $120^{\circ} / 70^{\circ}$ joint set included. This enabled studying which of these structures had the largest influence on the deformation pattern. 
The results were compared with deformation data, using both GPS and InSAR data. Consequently, deformation data was used to constrain the models, and arrive at the most plausible model - given that these structures are only partly validated through field observations and/or drilling. A comparison of two cases is shown in Figure 14. The results showed that the large-scale structures (DZ026, DZ024, DZ020 and DZ023) have little influence on the deformation development on the west side of the cave crater. They do, however, strongly influence deformations near the cave crater, particularly on the eastern side. The simulated caving sequence did not have a strong effect on the final deformations, only on the intermediate deformations during the mining sequence. The only case that resulted in significant deformations also on the western side was that with the $120 / 70^{\circ}$ joint included (Figure 14). These features also provide a delimitation of movements in the southerly direction, similar to the results from GPS and InSAR data (cf. Figure 12). These results are very illuminating, as they suggest a possible mechanism for caving-induced deformations in areas that are, relatively speaking, farther from active mining areas.

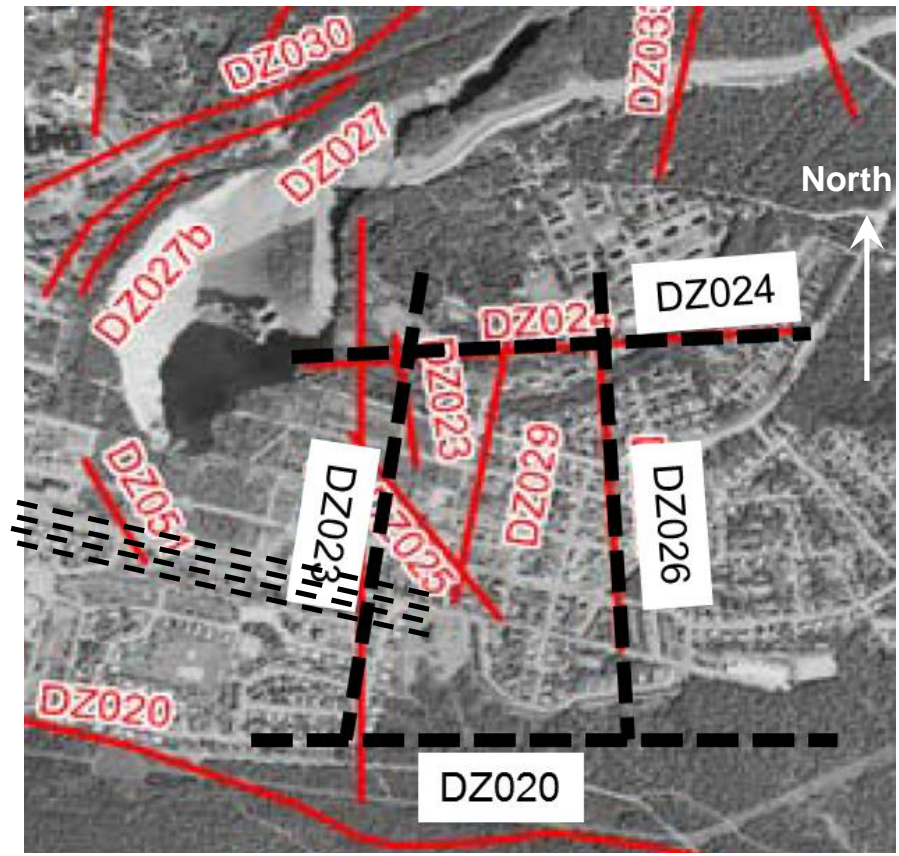

Figure 13 Shear zones (thick black lines) and the $120^{\circ} / 70^{\circ}$ joint set (thin black lines) included in the model

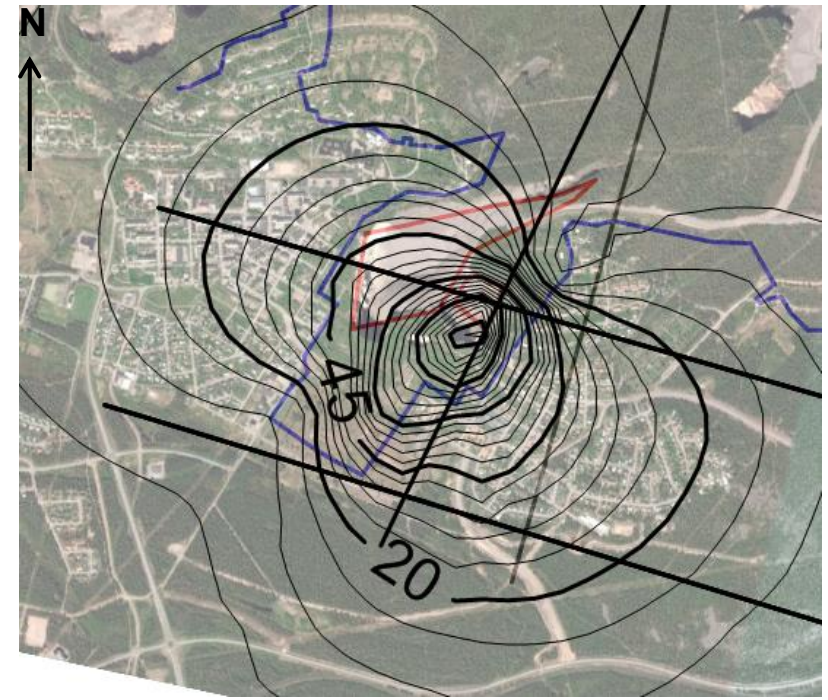

(a)

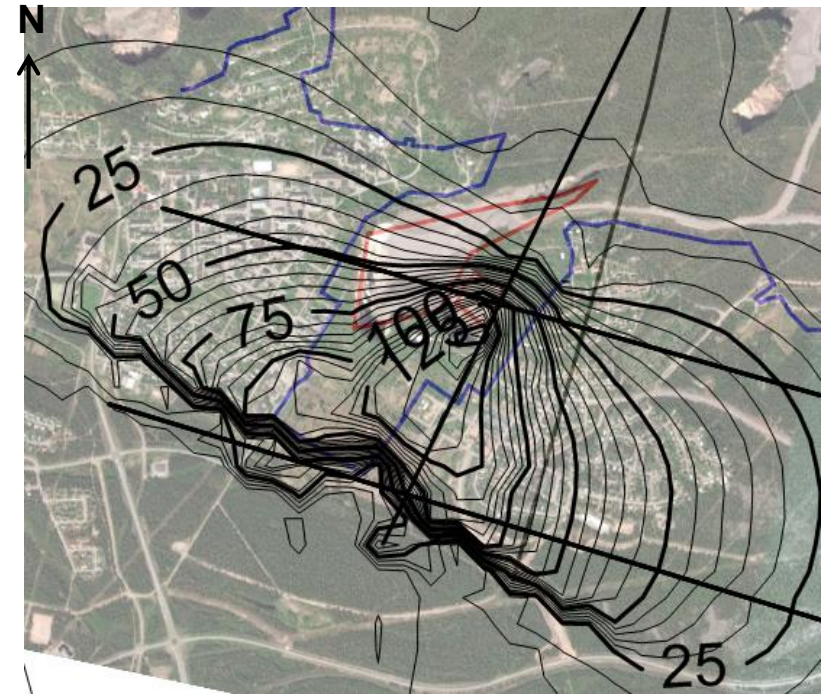

(b)

Figure 14 Calculated horizontal deformation for two cases: (a) With the four shear zones included; and, (b) With the shear zones and the $120^{\circ} / 70^{\circ}$ joint included 


\section{$6 \quad$ Concluding remarks}

An extensive monitoring program using InSAR is currently in use at the LKAB mining sites in Kiruna and Malmberget. This program will supplement the standard GPS monitoring, primarily to increase the understanding of the caving-induced deformation process. InSAR will provide a wider area of coverage, and more frequent measurement data, but cannot currently replace GPS monitoring year-round due to poor coherence during the winter period. The use of InSAR has made it possible to verify overall movement trends with respect to major shear structures in Malmberget. Additionally, increased reliability in areas with poor GPS coverage has been achieved, as well as increased data coverage in periods between GPS measurement campaigns, for both sites.

Undoubtedly, there are some limitations with InSAR that are not easily addressed, e.g. poor coherence during winter season at high-latitude (snow-covered) areas, and poor resolution in the north-south direction. Nevertheless, and despite these constraints, the use of InSAR at the LKAB mine sites has significantly advanced the knowledge of patterns and trends of the mining-induced ground deformations. Work is now ongoing to implement the use of InSAR to monitor the criterion for allowable ground deformations at both sites, as well as in integrated interpretation of caving mechanics and deformations. This will also include comparison with, and integration of, other survey methods such as unmanned aerial vehicle (UAV), that recently has come into more extensive use.

\section{Acknowledgement}

The financial support, as well the permission to publish this paper, by LKAB is gratefully acknowledged. The authors also acknowledge Mr Michael Henschel of MDA Geospatial Services, who performed a large part of the technical work during the initial InSAR monitoring for the Kiruna site, as well as Wendy Branson, also of MDA Geospatial Services, who was the acting project leader. Thanks are also due to Mr Anura Wickramanayke, who performed the majority of the research work in the same project, as well as to Jonas Ekman, Stefan Buehler, and Tore Lindgren, all at Luleå University of Technology, and Stephen Hobbs at Cranfield University, for academic supervision; Dr Priya Fernando of EADS Astrium for project support; and Bo Fjällborg and Anders Berg of LKAB. Finally, thanks are due to Mr Sebastian Hortberg, Itasca Consultants $A B$, for numerical modelling work.

\section{References}

Henschel, M, Dudley, J, Lehrbass, B, Sato, S \& Stöckel, B-M 2015, 'Monitoring slope movements from space with robust accuracy assessment', Proceedings of the 2015 International Symposium on Slope Stability in Open Pit Mining and Civil Engineering, The Southern African Institute of Mining and Metallurgy, Johannesburg, pp. 151-160.

Itasca Consulting Group, Inc. 2016, 3DEC, version 5.20, computer software, Itasca Consulting Group, Inc., Minneapolis, https://www.itascacg.com/software/3dec

Magnor, B \& Mattsson, H 2010, Strukturgeologisk Modell Över Malmbergets Gruvområde, final report to LKAB, GeoVista, Luleå, and Hifab, Stockholm, in Swedish.

Mäkitaavola, K, Stöckel, B-M, Sjöberg, J, Hobbs, S, Ekman, J, Henschel, M \& Wickramanayake, A 2016, 'Application of InSAR for monitoring deformations at the Kiirunavaara mine', in HS Mitri, S Shnorhokian, MK Kumral, A Sasmito \& A Sainoki (eds), Proceedings of the 3rd International Symposium on Mine Safety, Science and Engineering, McGill University, Montreal, pp. 133-139.

Sjöberg, J \& Savilahti, T 2014, 'Caving in the Fabian orebody from mining stope to cave crater in Malmberget', Proceedings of the 8th Asian Rock Mechanics Symposium: Rock Mechanics for Global Issues - Natural Disasters, Environment and Energy, Japanese Committee for Rock Mechanics, Tokyo, pp. 1421-1430.

Vatcher, J, McKinnon, S \& Sjöberg, J 2016, 'Developing 3-D mine-scale geomechanical models in complex geological environments, as applied to the Kiirunavaara Mine', Engineering Geology, vol. 203, pp. 140-150.

Wickramanayake, AAB, Mahapatra, P, Buehler, SA, Ekman, J, Hobbs, S \& Mendrok, J 2015, 'Comparison between Static-GPS and corner reflector InSAR (CR-InSAR) measurements at a high latitude site', submitted for publication.

Wickramanayake, AAB, Henschel, MD, Hobbs, S, Buehler, SA, Ekman, J \& Lehrbass, B 2016, 'Seasonal variation of coherence in SAR interferograms in Kiruna, Northern Sweden', International Journal of Remote Sensing, vol. 37 no. 2, pp. 370-387, https://dx.doi.org/10.1080/01431161.2014.915435 